\title{
KAJIAN DESAIN DINAMIKA KENDARAAN LISTRIK RODA EMPAT DAN STABILITAS KENDARAAN PADA KONDISI STASIONER
}

\author{
Sony Sukmara, Dr. LM. Firman, MT, Ferry Budhi Susetyo, MT \\ Universitas Pancasila
}

\begin{abstract}
ABSTRAK
Peningkatan jumlah penggunaan kendaraan bermotor sebagi alat transportasi berbahan bakar minyak (bahan bakar fosil) yang menghasilkan emisi gas buang menjadi salah satu faktor terjadinya pencemaran udara yang berdampak negatif terhadap lingkungan. Pencemaran udara dari sector transportasi berupa kendaraan bermotor berbahan bakar minyak (bahan bakar fosil) ini dipicu lagi dengan jumlah penggunaan bahan bakar yang sangat tinggi, menjadi penyebab terjadinya pencemaran udara yang diakibatkan penggunaan kendaraan bermotor. Kelangkaan bahan bakar minyak dan tingginya emisi gas buang merupakan dua hal utama yang dihadapi oleh dunia dewasa ini. Berbagai inovasi ditempuh dalam rangka mengembangkan kendaraan rendah emisi yang tidak tergantung pada sumber mineral. Sebagai wujud kepedulian terhadap masalah cadangan minyak bumi dan polusi di negara Indonesia, maka penulis bermaksud untuk mengkaji sebuah konsep kendaraan listrik roda empat dengan kapasitas berpenumpang empat orang yang sekaligus menjadi tonggak perubahan menuju Indonesia hijau lewat kendaraan ramah lingkungan.

Metodologi yang digunakan penulis adalah dengan metoda kajian perhitungan desain dinamika kendaraan listrik roda empat dan stabilitas kendaraan pada kondisi stasioner. Titik berat kendaraan yang dihasilkan akan memberikan pengaruh terhadap kestabilan kendaraan yang diukur dengan parameter safety factor yang sudah menjadi standar.

Dari hasil kajian ini dapat disimpulkan bahwa kendaraan listrik roda empat yang di desain mempunyai titik berat kendaraan pada sumbu koordinat $(x, y, z)$ yaitu $(1370,52,0,620,17)$ saat tanpa penumpang dengan nilai safety factor $68,53 \%$ dan saat penumpang penuh sumbu koordinat titik berat kendaraan yaitu $(1455,71,0,646,18)$ dengan nilai safety factor $61,75 \%$. Desain kendaraan ini layak untuk dilakukan pengujian selanjutnya.
\end{abstract}

Kata kunci : Dinamika, stabilitas dan stasioner.

\section{ABSTRACT}

An increasing number of motor vehicle use as a transportation fuel oil (fossil fuel) which produces emissions become one of the factors that have a negative impact of air pollution on the environment. Air pollution from the transportation sector in the form of motor vehicle fuel oil (fossil fuels) is triggered again by the number of fuel use is very high, the cause of the air pollution caused by motor vehicle use. The scarcity of fuel and exhaust gas emissions are the two main things that faced by the world today. Various innovations pursued in order to develop low-emission vehicles that do not depend on the source of the mineral. As we care about the problem of oil reserves and pollution in the country of Indonesia, the author intends to examine a four-wheeled electric vehicle concept with a passenger capacity of four people who also became a milestone towards Indonesia green change through environmentally friendly vehicles.

The methodology used by the author is the calculation method of the study design four-wheeled electric vehicle dynamics and stability of the vehicle in a stationary condition. The weight of vehicles produced will give effect to the vehicle stability safety factor measured by parameters that have become standard. 
From the results of this study it can be concluded that the four-wheeled electric vehicles that have a focus on the design of the vehicle on the coordinate axes $(x, y, z)$ is $(1370.52,0,620.17)$ when no passengers with safety factor value of $68.53 \%$ and when the full passenger vehicle center of gravity of the coordinate axes, namely $(1455.71,0,646.18)$ with a value of $61.75 \%$ safety factor. Vehicle design is feasible to do further testing.

Keywords: dynamics, stability and stationary.

\section{Latar Belakang}

Penggunaan BBM di sektor transportasi mencapai $65 \%$, pembangkit listrik $16 \%$, industri $10 \%$, rumah tangga $2 \%$, komersial $1 \%$, dan sektor lainnya $6 \%$, dari total kebutuhan BBM pada tahun 2011 yang

mencapai 70,89 juta KL. Dibandingkan tahun 2010, jumlah tersebut mengalami peningkatan $4,04 \%$ dari sebelumnya 68,14 juta KL.

Grafik 1 Konsumsi BBM berdasarkan Sektor 2011

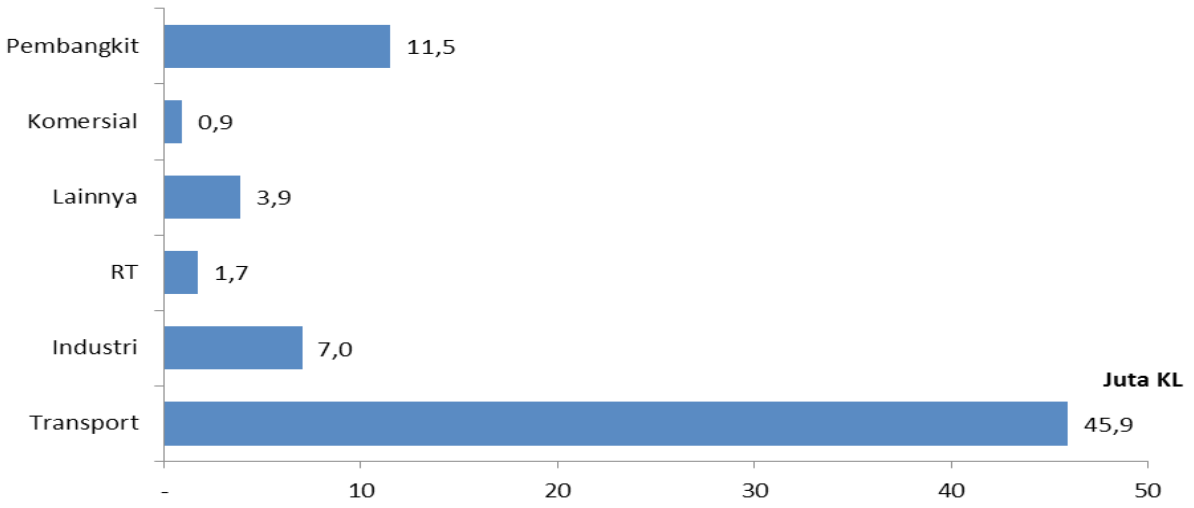

Sumber : Handbook of Energi \& Ekonomic Stastistic of Indonesia 2012

*pembangkit hanya untuk pembangkit PLN

BBM terbesar yang digunakan di sektor transportasi adalah jenis gasoline, termasuk di dalamnya BBM subsidi dan non subsidi. Pemakaian BBM jenis gasoline terus mengalami peningkatan setiap tahunnya. Dibandingkan tahun 2010, konsumsi gasoline di sector transportasi mengalami peningkatan $11,93 \%$ dari 23,1 juta KL menjadi 25,94 juta KL. Pemanfaatan biofuel juga menunjukan trend yang positif, meskipun sejak tahun 2009 pemanfaatan biofuel hanya terjadi pada jenis biodiesel.
Sebagai wujud kepedulian terhadap masalah cadangan minyak bumi dan polusi di negara Indonesia, maka penulis bermaksud untuk mengkaji sebuah konsep kendaraan listrik roda empat dengan kapasitas berpenumpang empat orang yang sekaligus menjadi tonggak perubahan menuju Indonesia hijau lewat kendaraan ramah lingkungan.

Pada tesis ini akan dilakukan kajian desain dinamika kendaraan listrik roda empat dan stabilitas kendaraan pada kondisi stasioner. Pada kajian ini ada beberapa faktor yang dapat mempengaruhi terhadap stabilitas 
kendaraan diantaranya dimensi kendaraan, beban kendaraan, titik berat kendaraan dan titik berat bodi kendaraan. Sedangkan yang menjadi indicator terpenuhinya stabilitas kendaraan ditentukan oleh nilai safety factor dari kendaraan pada kondisi stasioner sehingga kendaraan layak untuk dilakukan uji lapangan.

\section{Identifikasi Masalah}

Adapun masalah - masalah yang mempengaruhi stabilitas kendaraan tersebut adalah :
1.Jarak wheel base
2.Jarak wheel track
3. Posisi titik berat kendaraan
4. System pengereman
5. Aerodinamis
6. Sistem Kemudi

\section{Pembatasan Masalah}

Adapun yang akan dikaji pada desain dinamika kendaraan listrik roda empat dan stabilitas kendaraan pada kondisi stasioner adalah :

1. Kajian Dimensi Kendaraan

2. Kajian Berat Kendaraan

3. Menentukan posisi titik berat kendaraan pada kondisi tanpa penumpang

4. Menentukan posisi titik berat kendaraan pada kondisi penumpang penuh

5. Menghitung factor keamanan/safety factor

\section{Perumusan Masalah Penelitian}

Perumusan masalah dari penelitian ini, yaitu

a. Berapa Panjang, lebar dan Tinggi kendaraan yang sesuai dengan spesifikasi kendaraan sehingga keamanan tercapai ?

b. Berapa berat kendaraan kondisi tanpa dan dengan penumpang ? c. Terletak dimana titik berat pada kedaraan pada kondisi tanpa penumpang sehingga memberikan nilai safety factor yang tinggi ?

d. Terletak dimana titik berat pada kedaraan dengan penumpang penuh sehingga memberikan nilai safety factor yang tinggi?

\section{Tujuan Penelitian}

Penelitian ini bertujuan untuk mendapatkan keamanan pengendara yang optimal dengan tetap memperhatikan kestabilan kendaraan dan untuk mengkaji :

1. Desain dimensi kendaraan yang sesuai dengan spesifikasi kendaraan.

2. Berat pada kendaraan tanpa penumpang sehingga mendapatkan tingkat keamanan yang optimal.

3. Berat pada kendaraan dengan penumpang penuh sehingga mendapatkan tingkat keamanan yang optimal.

4. Letak dimana titik berat pada kedaraan kondisi kosong dan penuh sehingga memberikan nilai safety factor yang tinggi.

\section{Hipotesis}

Berdasarkan beberapa literatur yang ada, dapat disampaikan beberapa hipotesis dari rencana penelitian sebagai berikut :

a. Dimensi kendaraan yang ideal adalah dimensi yang telah dipersyaratkan dalam UndangUndang Nomor 55 Tahun 2012 tentang kendaraan yaitu Panjang tidak melebihi 12.000 (dua belas ribu) milimeter untuk kendaran bermotor tanpa kereta gandengan atau kereta tempelan selain mobil bus, lebar tidak melebihi 2.500 (dua ribu lima ratus) millimeter, tinggi tidak melebihi 4.200 (empat ribu dua ratus) milimeter dan tidak 
lebih dari 1,7 (satu koma tujuh) kali lebar Kendaraan;

b. Mengkaji berat kendaraan tanpa penumpang dan dengan penumpang penuh serta titik berat kendaraan yang dapat memberikan pengaruh terhadap safety factor sehingga keamanan pengendara tercapai.

\section{Batasan dan Ruang Lingkup Penelitian}

Untuk mencapai tujuan penelitian yang ditetapkan maka penelitian ini dibatasi pada kendaraan penumpang, kategori M1, dengan ruang lingkup sebagai berikut :
1. Mengkaji desain dinamika kendaraan pada kondisi stationer.

2. Mengkaji stabilitas kendaraan pada kondisi stasioner dan roda tidak berputar berdasarkan parameter safety factor.

\section{Dasar-dasar Dinamika Kendaraan}

Pokok-pokok uraian tentang dinamika kendaraan ini meliputi : kendaraan pada kondisi stationer dengan mengkaji desain yang optimal sehingga mendapatkan tingkat safety factor yang tinggi yang dapat memberikan tingkat keamanan yang tinggi pula.

\section{Sistematika Kajian Perancangan}

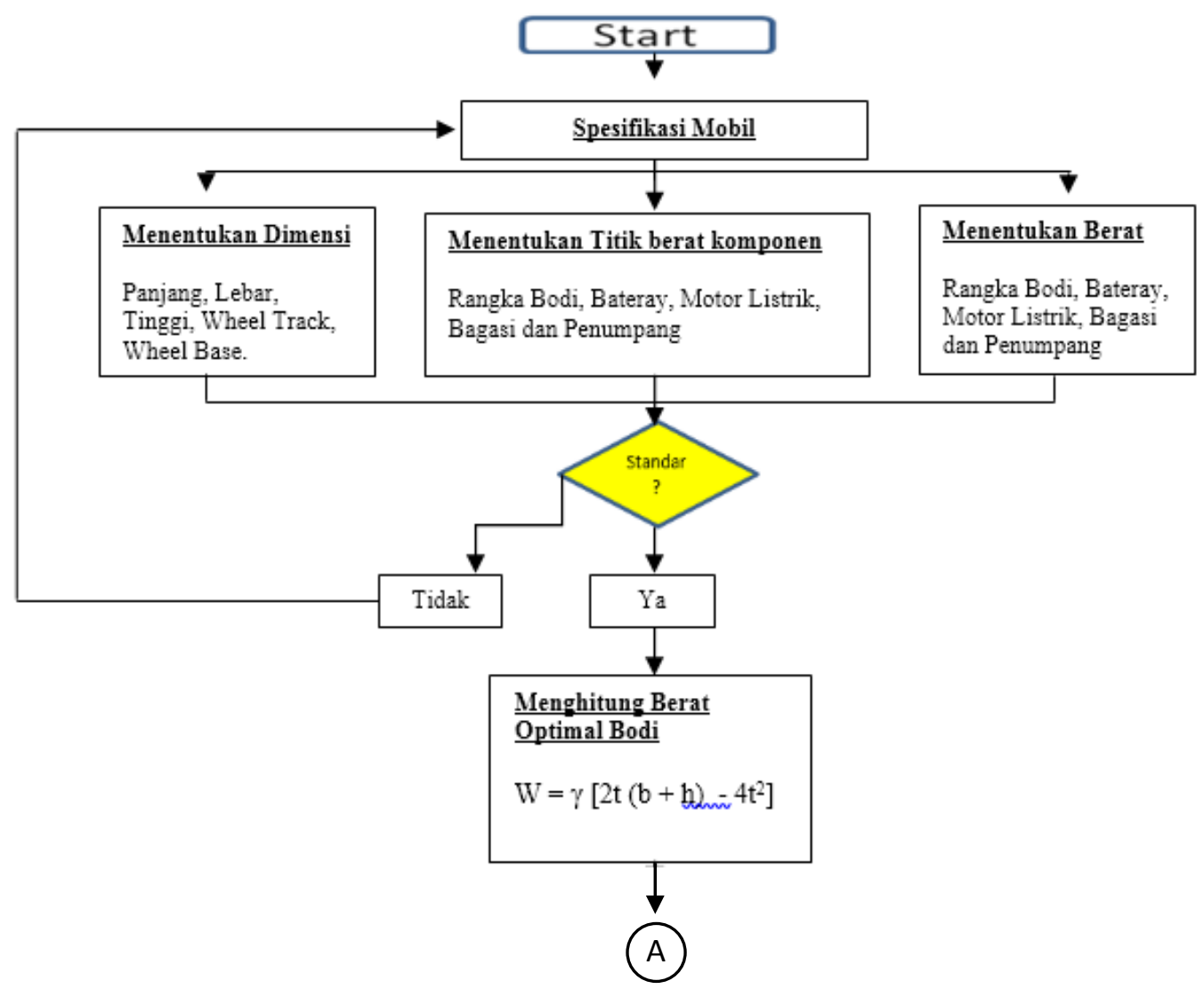




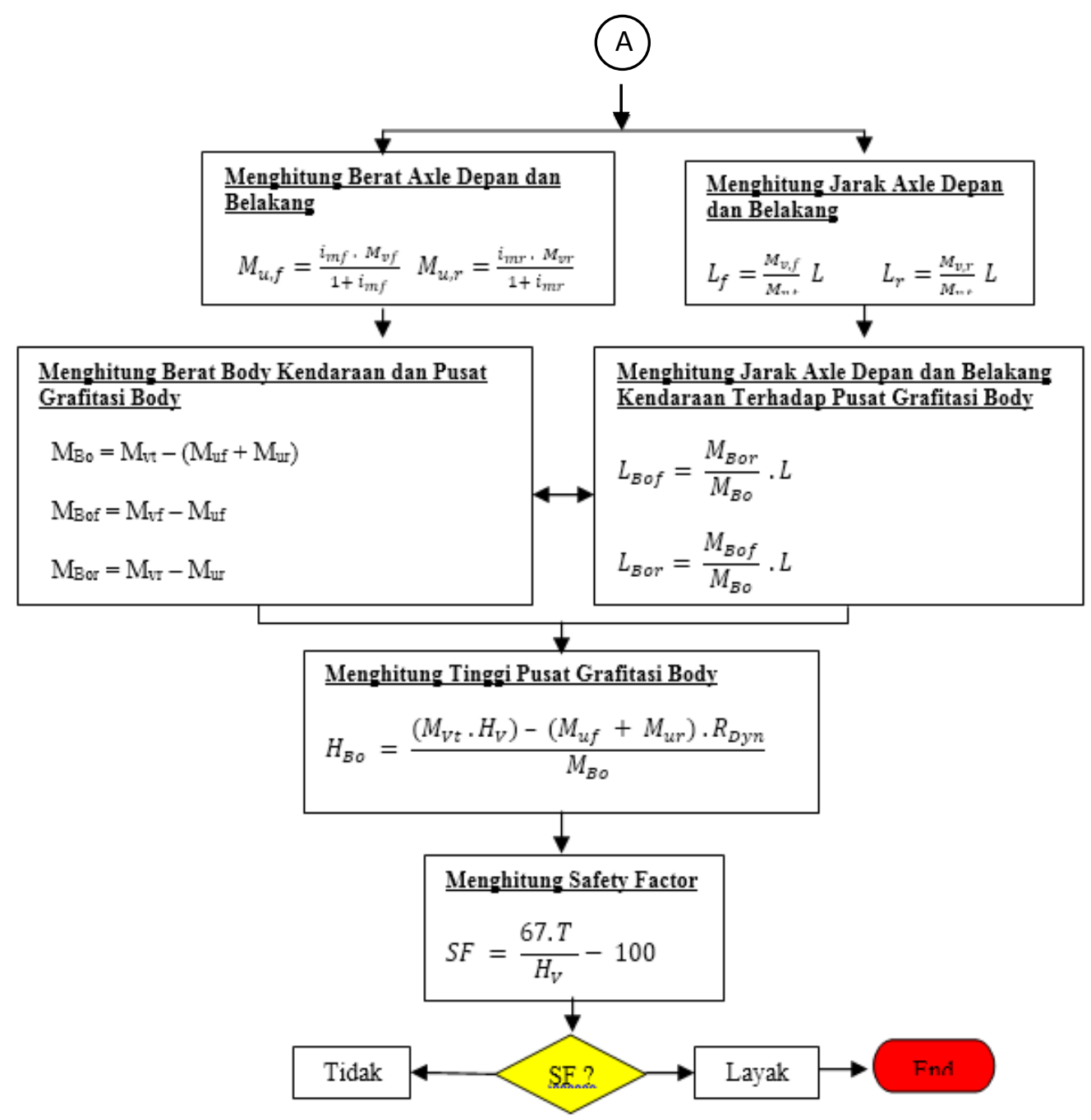

Gambar 1 Flowcart Alur Kajian Desain 


\section{Menentukan Titik Berat Kendaraan Tanpa Penumpang}

Dari gambar kendaraan yang sudah di desain dengan menggunakan skala gambar
$1: 20$ seperti pada gambar desain kendaraan di bawah ini, sehingga didapat data ukuranukuran serta berat komponen seperti pada table berikut :

Tabel. 1 Koordinat Titik Berat Komponen Kendaraan

\begin{tabular}{|c|c|c|c|c|c|c|c|}
\hline Nama Komponen & $\begin{array}{c}\text { Massa } \\
(\mathbf{k g})\end{array}$ & $\mathbf{X i}(\mathrm{mm})$ & Yi (mm) & $\mathbf{Z i}(\mathbf{m m})$ & mi . Xi & $\begin{array}{c}\text { mi . } \\
\text { Yi }\end{array}$ & $\mathbf{m i} \cdot \mathbf{Z i}$ \\
\hline $\begin{array}{l}\text { Motor Listrik, } \\
\text { CVT, Coupling, } \\
\text { Axle }\end{array}$ & 50 & 32,66 & 0 & 518,06 & 1633 & 0 & 25903 \\
\hline $\begin{array}{l}\text { Baterai, } \\
\text { Converter, } \\
\text { Regulator }\end{array}$ & 70 & 1862,19 & 0 & 330 & 130353 & 0 & 23100 \\
\hline $\begin{array}{l}\text { Bagasi, Ban } \\
\text { Cadangan }\end{array}$ & 50 & 2503,16 & 0 & 634,02 & 125158 & 0 & 31701 \\
\hline Rangka, Body & 300 & 1290 & 0 & 702,58 & 387000 & 0 & 210774 \\
\hline Total & 470 & 5688,01 & $\mathbf{0}$ & 2184,66 & 644144 & $\mathbf{0}$ & 291478 \\
\hline
\end{tabular}

\section{Safety Faktor}

Untuk dapat mengetahui kestabilan kendaraan sebelum diuji maka nilai dari parameter ini akan merekomendasi, apakah layak diuji lapangan atau tidak.

$$
\begin{aligned}
& S F=\frac{67 T}{H_{V}}-100 \\
& S F=\frac{67 \cdot 1560}{620,17}-100
\end{aligned}
$$

$$
S F=68,53 \%
$$

Pada tabel stabilitas nilai SF $68,53 \%$ berada pada zona very safe $(0,52<\mathrm{SF} \leq$ 0,74) artinya kendaraan dalam keadaan sangat aman dalam kondisi statis sehingga dapat dilakukan uji lapangan. 


\section{Menentukan Titik Berat Kendaraan Dengan Penumpang Penuh}

Tabel 2 Koordinat Titik Berat Kendaraan Dengan Penumpang Penuh

\begin{tabular}{|c|c|c|c|c|c|c|c|}
\hline $\begin{array}{c}\text { Nama } \\
\text { Komponen }\end{array}$ & $\begin{array}{c}\text { Massa } \\
\text { (kg) }\end{array}$ & Xi (mm) & Yi (mm) & $\mathbf{Z i}(\mathbf{m m})$ & $\mathbf{m i} . \mathbf{X i}$ & mi . Yi & $\mathbf{m i} \cdot \mathbf{Z i}$ \\
\hline $\begin{array}{l}\text { Motor } \\
\text { Listrik, CVT, } \\
\text { Coupling, } \\
\text { Axle }\end{array}$ & 50 & 32,66 & 0 & 518,06 & 1633 & 0 & 25903 \\
\hline $\begin{array}{l}\text { Baterai, } \\
\text { Converter, } \\
\text { Regulator }\end{array}$ & 70 & 1862,19 & 0 & 330 & 130353 & 0 & 23100 \\
\hline $\begin{array}{l}\text { Bagasi, Ban } \\
\text { Cadangan }\end{array}$ & 50 & 2503,16 & 0 & 634,02 & 125158 & 0 & 31701 \\
\hline $\begin{array}{l}\text { Rangka, } \\
\text { Body }\end{array}$ & 300 & 1290 & 0 & 702,58 & 387000 & 0 & 210774 \\
\hline $\begin{array}{l}\text { Penumpang } \\
\text { Depan }\end{array}$ & 150 & 1166 & 0 & 652,27 & 174900 & 0 & 97840,5 \\
\hline $\begin{array}{l}\text { Penumpang } \\
\text { Belakang }\end{array}$ & 150 & 2012,37 & 0 & 721,62 & 301855,5 & 0 & 108243 \\
\hline Total & 770 & 8866,38 & 0 & 3558,55 & 1120899,8 & $\mathbf{0}$ & 497561,5 \\
\hline
\end{tabular}

\section{Safety Faktor}

$$
\begin{aligned}
& S F=\frac{67 T}{H_{V}}-100 \\
& S F=\frac{67 \cdot 1560}{646,18}-100 \\
& S F=61,75 \%
\end{aligned}
$$

Pada tabel stabilitas nilai SF $61,75 \%$ berada pada zona very safe $(0,52<$ $\mathrm{SF} \leq 0,74)$ artinya kendaraan dalam keadaan sangat aman dalam kondisi statis sehingga dapat dilakukan uji lapangan.

\section{Analisis Hasil Perhitungan}

Dari hasil desain kendaraan listrik roda empat didapat titik koordinat untuk titik berat kendaraan dan bodi tanpa penumpang 
yaitu koordinat $(\mathrm{x}, \mathrm{y}, \mathrm{z})$ yaitu $(1370,52,0$, $620,17)$ dan $(1375,88,0,648,15)$. Titik berat kendaraan dan titik berat body dengan penumpang penuh adalah $(1455,71,0$, $646,18)$ dan $(1534,06,0,717,87)$ dapat dianalisis, bahwa pada saat berpenumpang penuh terjadi perubahan koordinat titik berat gravitasi baik pada kendaraan ataupun pada bodi disebabkan kendaraan mendapatkan beban tambahan sehingga berpengaruh terhadap besaran safety factor.

Namun demikian dalam kajian desain ini safety factor pada saat beban penumpang penuh yang didapat dari hasil perhitungan masih dalam range very safe.

\section{Kesimpulan}

1. Dimensi kendaraan listrik ini adalah sebagai berikut : panjang kendaraan adalah $3.350 \mathrm{~mm}$, lebar kendaraan adalah 1.714 $\mathrm{mm}$ dan tinggi kendaraan adalah $1.461 \mathrm{~mm}$, wheel track adalah $1.560 \mathrm{~mm}$ dan wheel base adalah $2.450 \mathrm{~mm}$.

2. Titik berat kendaraan dan titik berat body tanpa penumpang adalah pada koordinat $(\mathrm{x}, \mathrm{y}, \mathrm{z})$ yaitu $(1370,52,0,620,17)$ dan $(1375,88,0$, 648,15). Titik berat kendaraan dan titik berat body dengan penumpang penuh adalah $(1455,71,0,646,18)$ dan $(1534,06,0,717,87)$.

3. Safety factor pada kondisi stasioner tanpa penumpang yaitu $68,53 \%$ dan dengan penumpang penuh mempunyai safety factor $61,75 \%$, desain dinamika kendaraan listrik roda empat pada kondisi stasioner mengisyaratkan bahwa tingkat keamanan kendaraan atau safety factor sangat baik yaitu pada interval $51 \%$ sampai $74 \%$ artinya bahwa kendaraan ini layak untuk diuji lapangan.

\section{Saran}

Kajian desain ini hanya pada dinamika kendaraan listrik roda empat dan stabilitas kendaraan pada kondisi stasioner dangan roda diam, sehingga disarankan perlu juga dilakukan kajian dinamika kendaraan listrik roda empat dan stabilitas kendaraan pada stasioner tetapi dengan roda berputar.

\section{Daftar Pustaka}

[1] Aga, M.; Okada, A. Analysis of vehicle stability control effectiveness from accident data, ESV Conference, Nagoya (2003).

[2] Farmer, Ch.: Effect of Electronic Stability Control on Automobile Crash Risk, IIHS Insurance Institute of Highway Safety, Arlington, Virginia, USA(2004).

[3] Ginting, rosnami. Perancangan produk. penerbit graha ilmu, edisi satu.,yogyakarta 2010

[4] Handbook of Comparative World Steel Standards 18/8/2013

[5] Handbook of Energy \& Economic Statistic of Indonesia 2012

[6] Jurnal Polusi Udara Akibat Aktivitas Kendaraan Bermotor Di Jalan Perkotaan Pulau Jawa dan Bali, Nanny Kusmingrum, G. Gunawan.

[7] Miranda, Dr jose Carlos product design techiques for robustness, reliability and optimization., 2004

[8] Onwubiko, chinyere. Introduction to engineering design optimization. Upper saddle river, united stated of america., 2000

[9] Sutantra I Nyoman dan Bambang Sampurno, Teknologi Otomotif. Penerbit Guna Widya., surabaya, 2010

[10] Ulrich. T karl Steven D. Eppinger perancangan \& pengembangan produk. Penerbit salemba teknika., jakarta 2001

[11] Widodo, imam djati. Perencanaan dan pengembangan produk.UII Press yogyakart., yogyakarta, 2003 